(REVIEW ARTICLE)

\title{
Gastro-retentive drug delivery system: A better approach of drug delivery system
}

\author{
Rajiv Kumar ${ }^{1,}{ }^{*}$, Rohit Kumar Chopra ${ }^{1}$, Harpreet Singh ${ }^{1}$, Parminder Nain ${ }^{2}$ and RK Dhawan ${ }^{1}$ \\ ${ }^{1}$ Khalsa College of Pharmacy, Amritsar, Punjab, India. \\ 2 Maharishi Markandeshwar University, Mullana, Ambala, Harayana, India.
}

Magna Scientia Advanced Biology and Pharmacy, 2021, 04(01), 025-034

Publication history: Received on 13 August 2021; revised on 23 September 2021; accepted on 25 September 2021

Article DOI: https://doi.org/10.30574/msabp.2021.4.1.0045

\begin{abstract}
The oral route is the best and most popular route for the administration of drugs in the systemic circulation. There are number of drugs which are given through the oral route. Gastro-retentive drug delivery system is very important system for the drug delivery system. The gastro-retentive drugs prolonged the drug time in the git and also improve their their bioavailability. These are widely used for site specific for the treatment of git disorders and diseases. There are number of approaches for gastro retentive drug delivery system such as floating system, mucoadhesive system, swelling system, high density system etc. In this review we discussed about approaches and various perspectives of gastro retentive drug delivery system.
\end{abstract}

Keywords: Gastroretentive drug delivery system; Floating system; Gastric residence time; Mucoadhesive system; Swelling system

\section{Introduction}

The most popular route for drug administration is oral route for systemic action .About $90 \%$ of the drugs are given by oral route. The oral route is the most prescribed route because it is easy to administer, easy to handling and versatile for various types of drugs. The short gastric retention time and unpredictable short gastric emptying time are the two problems of drug delivery systems. Decrease response of dose Due to incomplete drug release from the dosage form in the absorption zone [1-3].

However some of the drugs have poor bioavailiability due to incomplete absorption or degradation in GIT .Therefore to overcome this problem we use Gastroretentive Drug Delivery System(GRDDS) which are use to prolong the gastric retention time of the drugs which are:

- Locally active in stomach.

- Unstable in the intestinal environment.

- Have low solubility in high pH regions.

- Have narrow absorption window in the git.

Over the last two decades, the number of GRDDS have be designed to prolonged GRT . The main aim of preparing GRDDS is to minimize the problems associated with existing oral sustained release dosage form and to develop patient benefited drug delivery $[4,5]$.

\footnotetext{
${ }^{*}$ Corresponding author: Rajiv Kumar

Khalsa College of Pharmacy, Amritsar, Punjab, India.
} 


\subsection{Drugs suitable for the gastroretentive drug delivery system}

- Drugs that are primarly absorbed in the stomach. eg: Amoxicillin.

- Drugs that are narrow absorption window. eg: Levodopa, Methotrexate.

- Drugs that are poorly soluble in alkaline pH. eg: Furosemide, Diazepam.

- Drugs that are degrade in the colon. eg: Ranitidine, Metformin.

- Drugs rapdly absorbed from GIT tract. eg: Tetracylin

- Drugs acting normally in the stomach [6].

\subsection{Advantages of GRDDS}

- It can improved drug absorption.

- It has control drug delivery system.

- It can minimize the mucosal irritation.

- It is used for the treatment gastrointestinal diseases.

- It is east to administration and better patient compliance.

- This site specific drug delivery reduce undesirable site effects.

- $\quad$ Ease to administraton \& better patient complaince.

\subsection{Disadvantages of GRDDS}

- GRDDS is not suitable for drugs with stability or solubility problems in the stomach.

- Drugs that show irritant effect on gastric mucosa are not suitable for GRDDS.

- Drugs that are absorbed along the entire GIT ,that undergo first pass metabolism may not desirable [7].

\subsection{Anatomy of the GIT tract}

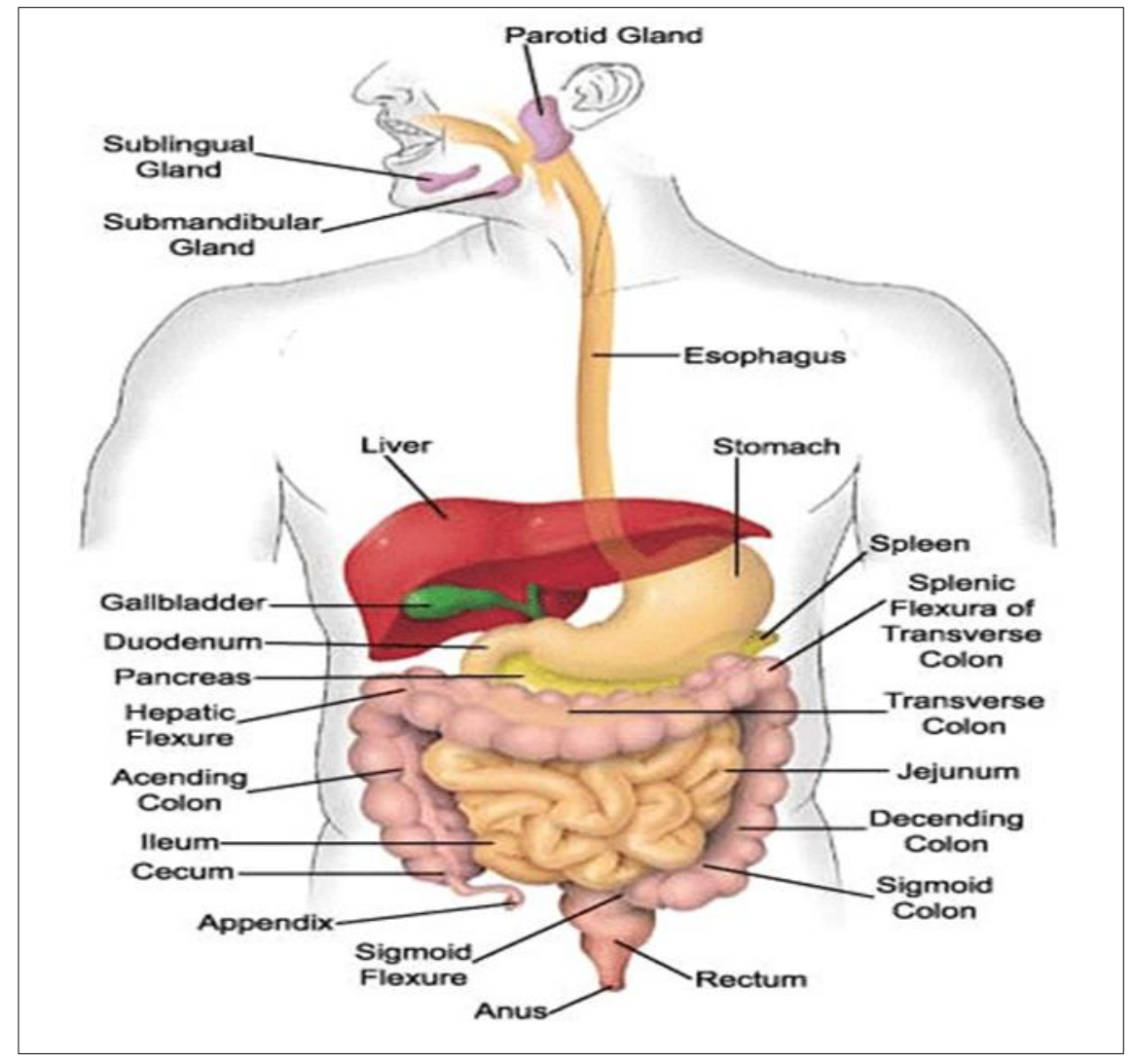

Figure 1 Gastrointestinal tract of human body

The gastrointestinal tract can be divided into 3 main regions:

- $\quad$ Stomach 
- Small intestine

* Duodeum

* Jejunum

* Ileum

- Large intestine

The gastrointestinal tract is a muscular tube of about $9 \mathrm{~m}$ long which extends from mouth to anus (Figure 1). Its function is to take nutrients and eliminate out the waste products by the different processes such as digestion, absorption, secretion and excretion. The stomach has three muscle layers called as oblique muscle and it is situated in the proximal part of the stomach, branching over the fundus and higher region of the gastric body [8].

\section{Gastric mortality and gastric empty rate}

Two distinct patterns of GIT mortality and secretion exist fasted and fed state. The bioavailiability of the orally administered drug is depend upon the state of feeding. In the fasted state, it is characterized by an interdigestive series of electric event called interdigestive myoelectric cycle or migrating motar complex (Figure 2).

It is divided into 4 phases:

- $\quad$ Phase 1 (basal phase )

- $\quad$ Phase 2 (preburust phase)

- $\quad$ Phase 3(burst phase )

- $\quad$ Phase 4

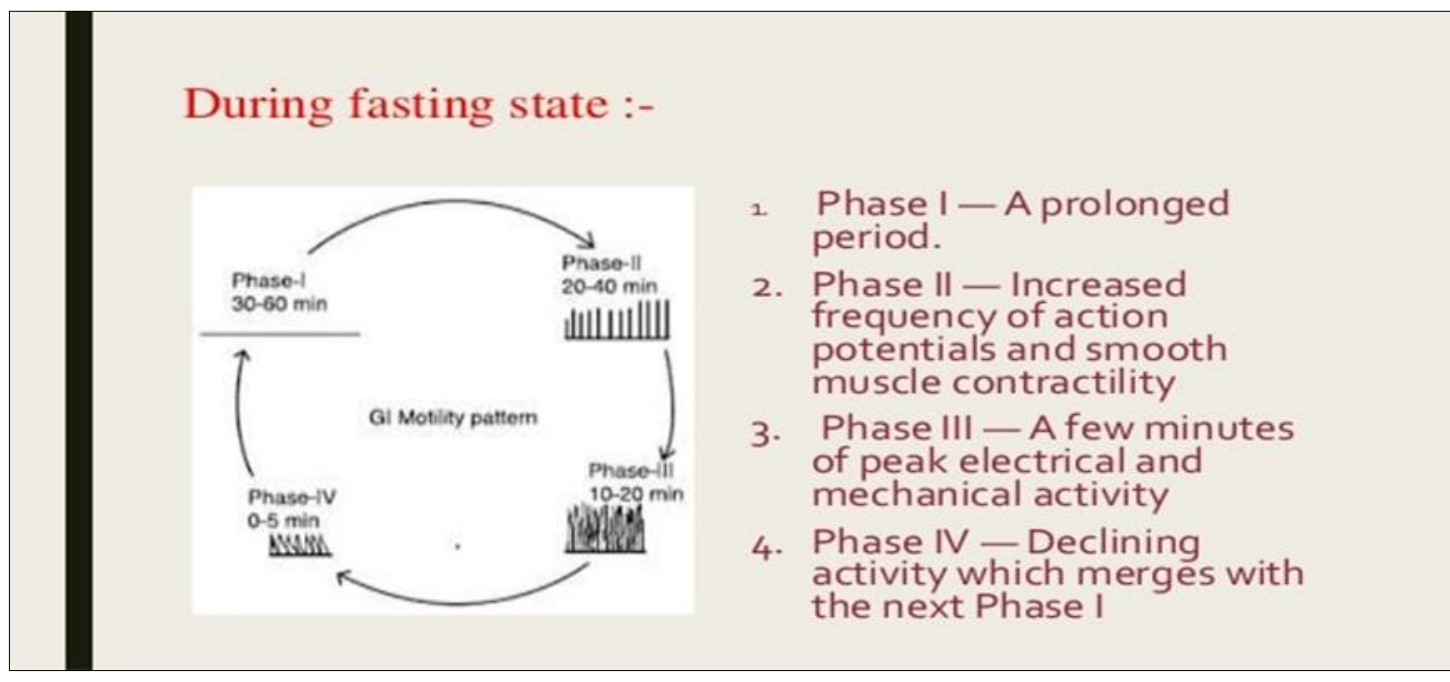

Figure 2 Gastric mortality and gastric empty rate

After the ingestion of the meal the pattern of contraction changes from fed to that of fasted state, this is known as digestive motility pattern, these contractions reduces the size of the food particles, after that it is propelled to the pylorus in the suspension form. During fed state the onset of MMC is delayed which result in slow down of gastric emptying rate $[9,10]$.

\section{Factors afeecting the Gastroretentive system}

There are various factors which affect the GRDDS :

- Density - Gastric retention time of drug is depend on the density. The density is always less than that of gastric content.

- $\quad$ Size - The drugs which have diameter of more than $7.5 \mathrm{~mm}$ have more gastric resistance time as compared to drugs of diameter $9.5 \mathrm{~mm}$

- Shape of dosage form - The tetrahedron and ring shaped dosage foam have longer period than other dosage foam of same size. 
- Nature of meal - Presence of food in the stomach affects the gastroretentive drug delivery system. Feeding of indigestiable polymers or fatty acid salts can change the mortality pattern of the stomach to the fed state, thus decreasing the gastric emptying rate and prolong drug release.

- Caloric content - The GRT can be increased with meal contain high protein and fats upto 4 to 10 hours.

- Frequency of feed - the GRT can increased over 400 minutes when successive meal are given as compared with a single meal due to the low frequency of MMC (migrating motor complex).

- Age - The GRT can be longer to the elderly people , mostly over the of 70 .

- Posture - GRT can vary between supine and upright ambulatory states of the patients.

- Biological factors - Diabetes and Crohn's disease , etc.

- Concomitant drug administration - Floating time is affected by antichilonergics drugs such as atropine and propantheline ,opiates like codein etc [11-14].

\section{Approaches to achieve gastric retention}

Different approaches have been used to achieve or to increase the gastric retentionof oral dosage forms in the stomach.some of the drugs are formulated as single dosage or some are formulated as multi-component dosage forms. GRDDS can be classified in following approaches (Figure 3):

- High density system

- Bioadhesive/mucoadhesive system

- Raft forming system

- Magnetic system

- Floating/low density system

- Effervescent system

* Non effervscent system

- Expanding system

* Swelling system

* Unfoldable system

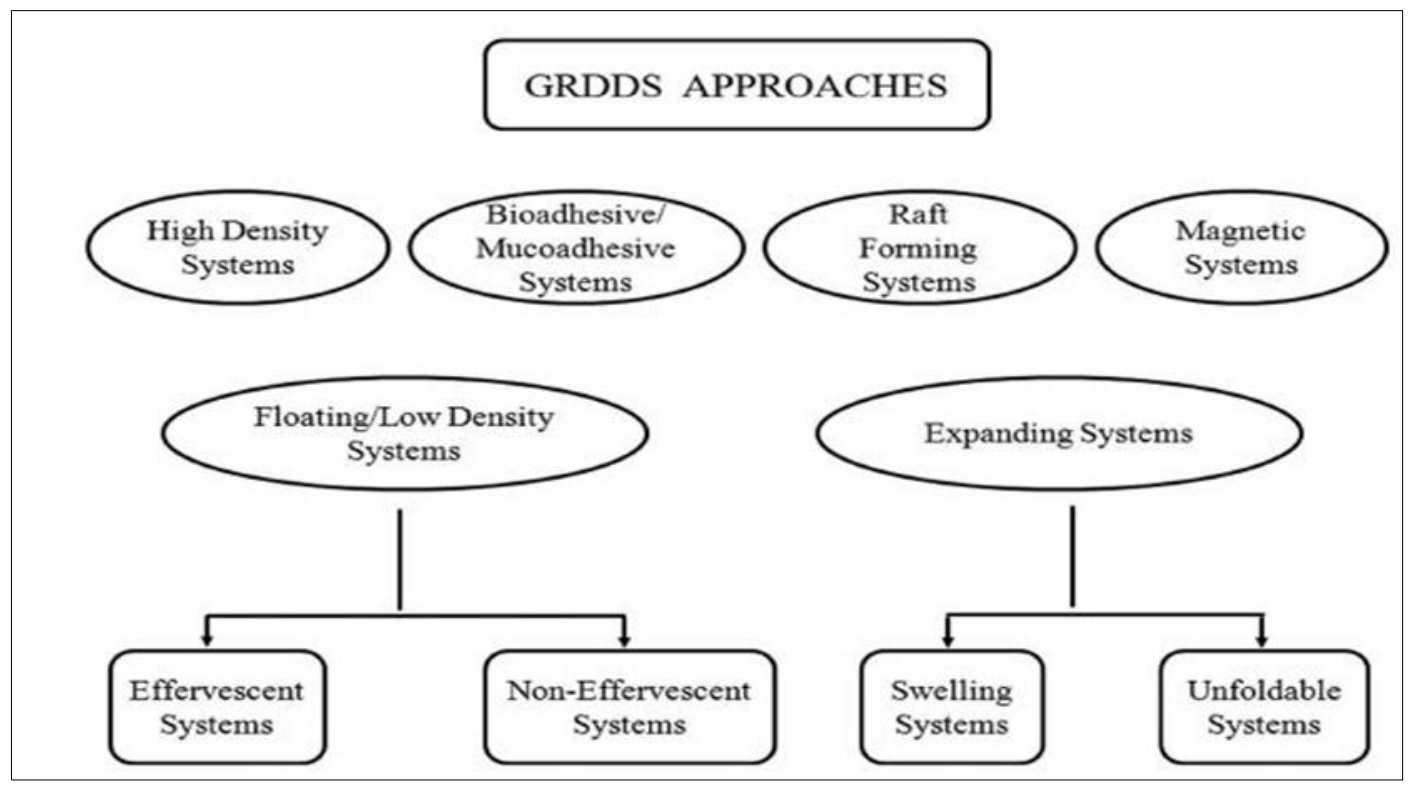

Figure 3 Approaches to gastric retention delivery system

\section{High density system}

In this dosage forms the density of formulation is higher than the density of the normal stomach content (Figure 4). These dosage forms are prepared by coating the drug with the heavy core or mixed with heavy inert material such as zinc powder, iron oxide, titanium dioxide etc. 
These system have some drawbacks like difficul to manufacture in large amount due to intract with gastric fluid to release its drug content and also this system is not availiable in the market [15].

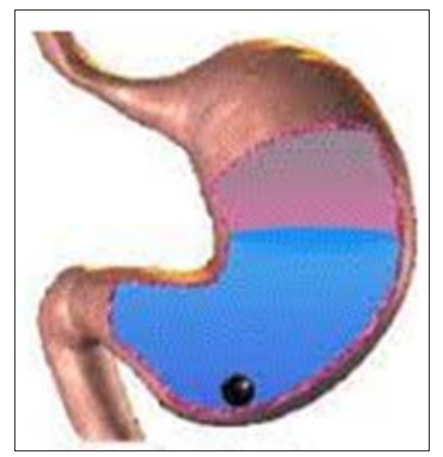

Figure 4 High density system

\section{Bioadhesive/mucoadhesive system}

In mucoadhesive system, drugs contain mucoadhesive polymers which binds to the gastric mucosal surface and increases its GRT in the git (Figure 5). The mucoadhesive polymers are very useful exicipient in the GRDDS. These polymers can be natural or can be synthetic.

Natural polymers are sodium alginate, gelatin, guar gum, tara gum, karaya gum .

Synthetic polymers are HPMC, carbopol, vinyl pyrolidine, sodium carboxyl methylcellulose [16].

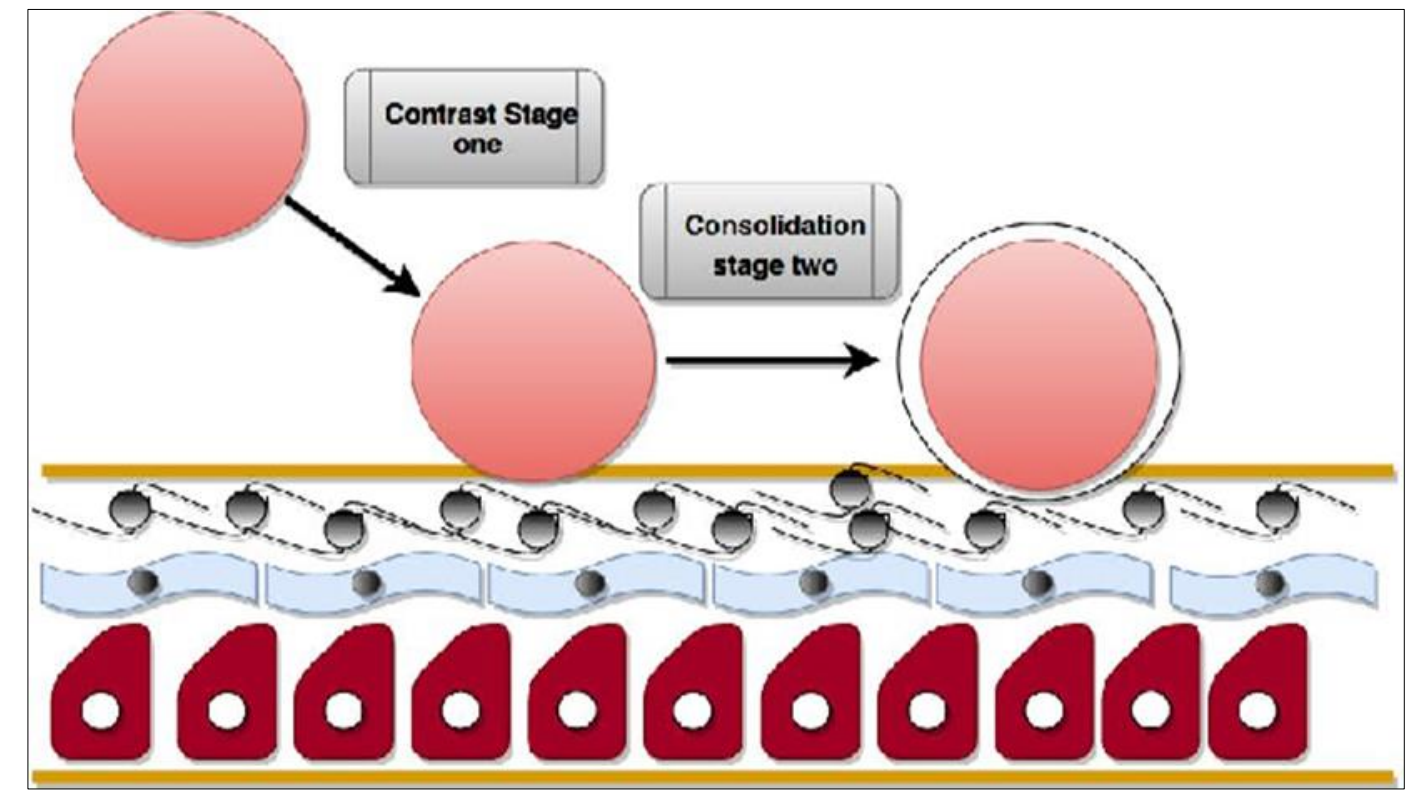

Figure 5 Bioadhesive/mucoadhesive system

\section{Raft forming system}

Raft forming system is not only helpful for sustained release drug but also useful for pediatric and geriatric patients. This system is also used in the liquid dosage form. Sustained and prolonged release of drug, good stabiity and bioavailiability makes the gaft forming sysetem very suitable for gastric retention of the drug (Figure 6). Nowadays raft forming system have received much attention for the delivery of antacids and drug delivery for GIT infections and disorders [17]. 


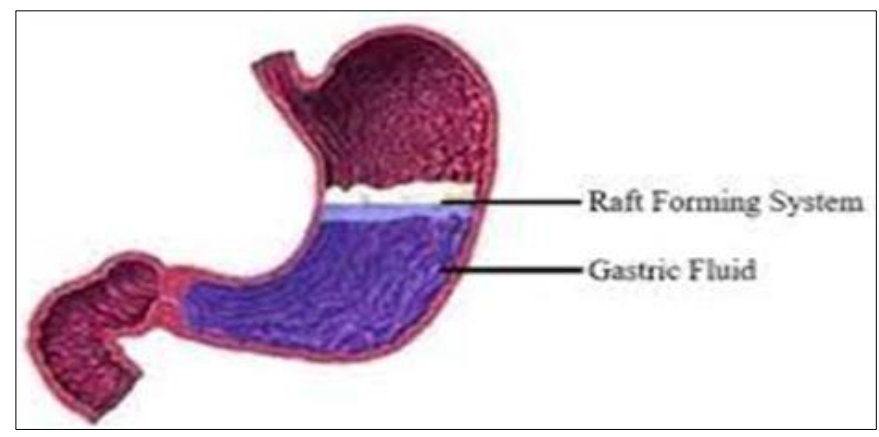

Figure 6 Raft forming system

\section{Magnetic system}

In the magnetic system, the dosage form contain a small internal magnet or a magnet placed on the abdomen over the position of the stomach (Figure 7). They guided them to the oesophagus with an external magnet for the initial 2 minutes and almost all the granules were retained in the region after 2 hours $[18,19]$.

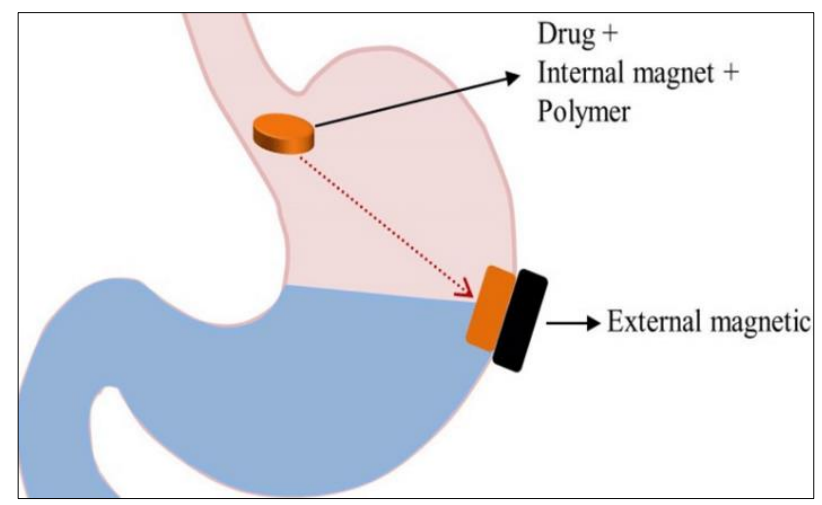

Figure 7 Magnetic system

\section{Floating/ low density system}

By the name low density system, these drugs remains float above the gastric contents for prolong peroid of time and provide continuous release of thr drug (Figure 8). These system are broadly used due to less or no adverse affect in the git. These dosage forms are also known as gas powered system, which can float in the contents of the stomach and release the drug in a controlled manner for prolonged period of time. This system is also known as hypodynamically balanced systems $[20,21,22]$.

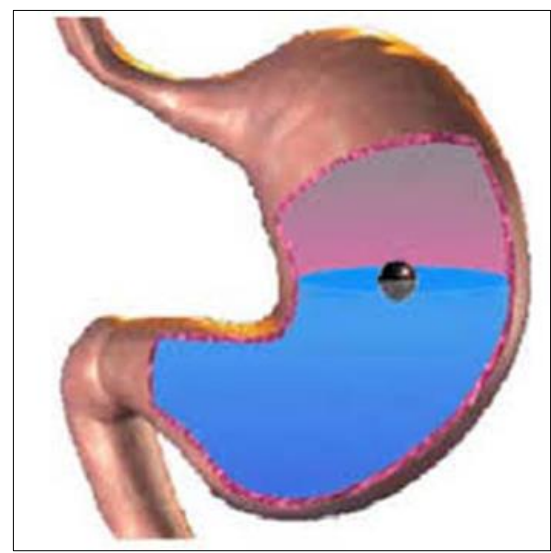

Figure 8 Floating or low density system 
Floating system are of two types:

- $\quad$ Effervescent system

- $\quad$ Non- effervescent system

\subsection{Effervescent system}

When these drugs come in contact with gastric juice of stomach, carbondioxide gas is released .This provide buoyancy to the dosage form that float on the gastric fluid. These effervescent system have further divided into different types:

\subsection{Volatile liquid containing system}

The GRT of a drug delivery system can be sustained by incorporating an inflatable chamber , which contain a liquid. eg. Ether, cyclopentane, that gasifies at body temperature to cause the inflatation of the chamber in the stomach. the device made up of Polyvinyl alcohol, Polyethylene that gradually dissolves causing the inflatable chamber to release gas and collapse after a predetermined time to permit the spontaneous ejection of the inflatable system from the stomach.

\subsection{Gas generating system}

These system utilize effervescent reactions between carbonate/bicarbonate salts and citric/tartaric acid to liberate $\mathrm{CO}_{2}$, which gets intrapper in the jellified layer of the system thus decreasing its specific gravity and making it float over gastric content.

\subsection{Non effervescent system}

The non effervescent system is based on the mechanism of swelling of polymer to mucosal layer in GIT. The most commonly used exicipients are hydrophilic gums, polysaccharides and matrix forming materials such as polycarbonate, polyacryate, as well as bioadhesive molecule such as Chitosan [23-25].

\section{Expanding/swelling system}

These dosage form after administrated to such an extent that it prevents to passage through the pyrolus, as a result the dosage form is remained in the stomach for a prolong period of time (Figure 9). These system are also called as plug type system because they remain have the tedency to lodged at the pyrolic sphincter. These formulations are designed for gastric retention and controlled delivery system for drugs in gastric cavity. Sustained and controlled release drug may be achieved by selecting a polymer with proper molecule weight and swelling property. When it comes in contact with gastric fluid the polymer imbibes water ad swell. The extensive swelling of these polymers is a result of the presence of physical-chemical crosslinks in the hydrophillic polymer network [26, 27].

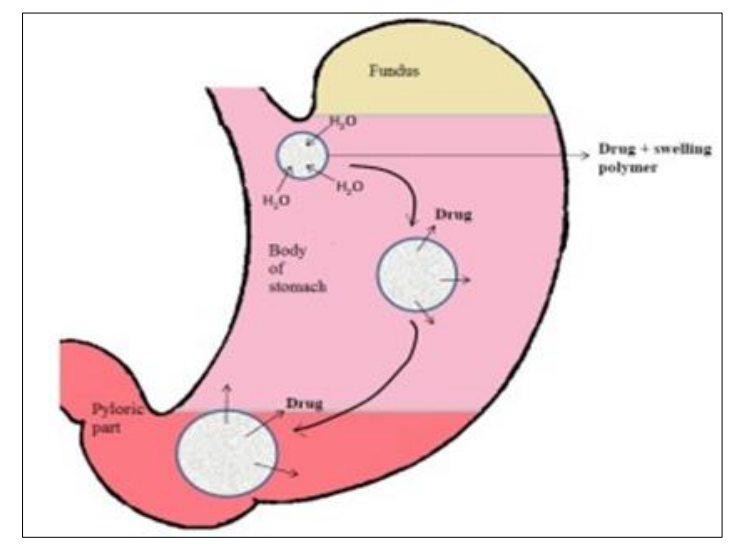

Figure 9 Expanding /swelling system 


\section{Evaluation parameter of GRDDS}

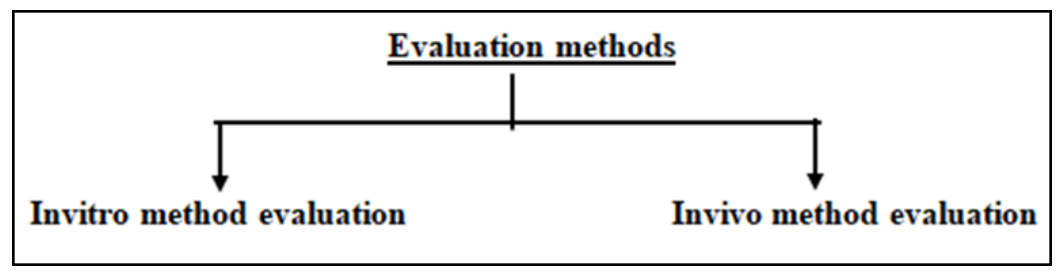

\subsection{In vitro method of evaluation}

\subsubsection{Fourier transform infrared analysis}

This technique is mostly used to identify organic, polymeric, functional group, and some inorganic material. By this technique we used to measure the drug purity, polymer and drug loaded formulations. The pallets are prepared under hydraulic press of $150 \mathrm{~kg} / \mathrm{cm}^{2}$ and the spectra are scanned over the wavenumber range of $3600-400 \mathrm{~cm}^{-1}$ at ambient temperature $[28,29]$.

\subsubsection{Particle size analysis and surface characteristics}

The particle size and size distribution of beads or microspheres are determined in the dry state using optical microscopy method . the external morphology is done by scanning electron microscope [30].

\subsubsection{Swelling studies}

Swelling of tablets occurs by the absorption of liquid resulting increase in weight amd volume. The liquid enters in the particles through pores and bind to the larger molecules which break the hydrogen bond resulting swelling of tablet particles. Tablet is weighted and placed in a beaeker containing $200 \mathrm{ml}$ of $0.1 \mathrm{~N} \mathrm{HCL}$, after a time interval the tablet is taken out from the beaker, soaked by the filter paper and weighed again [31, 32].

\subsubsection{Determination of drug content}

Drug content determines that the how much amount of drug is present in the formulation. The amount should not exceed the limit given in the monograph. The drug content is determined by HPTLC, HPLC and by various spectroscopy techniques [33].

\subsection{In vivo method of evaluation}

\subsubsection{X rays/gamma scintigraphy}

It heps to locate dogage form in GIT which can predict and correlate the gastric emptying time qund the passage of dogage form in the git. The inclusion of a radio opaque material into solid form which enables to visualize by $\mathrm{X}$ - rays . The inclusion of a gamma emitted radionuclide in the formulation allows indirect external observation using gamma camera, the gamma rays emitted by radionuclide is focused on camera which help to monitor the location of the dosage form $[34,35]$.

\subsubsection{Gastroscopy}

Gastroscopy is a peroral endoscopy used with fibre optics or video system. Gastroscopy is used to inspect visually the effect of prolongation in stomach. It can also give the detailed evaluation of GRDDS [36].

\section{Conclusion}

Based on the literature, we concluded that the GRDDS is one of the efficient technique to maintain the sustained release of drug in gastric environment and increases its absorption and bioavailiability. All thr GRDDS aproaches are convenient and reliable when compared to the other drug delivery system. A controlled drug delivery system with prolonged gastric retention may have great practical importance for the drugs which have narrow absorption window in upper small intestine. Ciprofloxacin, levodopa , furosemide are example of such drugs. GRDDS have systemic, localized and specific action. It helps in the treatment of various gastrointestinal diseases. From over last two decades various gastroretentive dosage forms have been designed to increase the gastric retention time. GRDDS is effective and simple drug delivery system. 


\section{Compliance with ethical standards}

\section{Acknowledgments}

We are highly thankful to Khalsa college of Pharmacy for providing the necessary facilities in premises for collecting data and writing this review.

\section{Disclosure of conflict of interest}

The authors declare no conflict of interest, financial or otherwise.

\section{References}

[1] Streube A, Siepmann J, Bodmeier R. Drug delivery to the upper small intestine window using gastroretentive technologies. Current opinion in pharmacology. 2006; 6(5): 501-8.

[2] Bardonnet PL, Faivre V, Pugh WJ, Piffaretti JC, Falson F. Gastro retentive dosage forms: Overview and special case of Helicobacter pylori. Journal of Controlled Release. 2006; 111(1-2): 1-18.

[3] Timmermans J, Moes AJ. How well do floating dosage forms float?. International Journal of Pharmaceutics. 1990; 62(2-3): 207-16.

[4] Chen YC, Ho H, Lee TY, Sheu MT. Physical characterizations and sustained release profiling of gastroretentive drug delivery system with improved floating and swelling capabilities. International Journal of Pharmaceutics. 2013; 441(1): 162-9.

[5] Kumar K, Jaimini M. Gastroretentive drug delivery system and its approaches: a review. International Journal of Pharmaceutical Research and Development. 2013; 4(12): 7-18.

[6] Subhramananym CVS, Vasantharaju SG. Laboratory manual of physical pharamaceutics. Delhi: Vallabh parkashan. 2002.

[7] Shahaa SH, Patel JK, Shudra KP, Patel NV. An overview of a gastroretentive floating drug delivery system. Asian Journal of Pharmacutical Sciences. 2009; 4(1): 65-80.

[8] Pawar UK, Shaswat K, Garg G, Awasthi R. Gastroretentive dosage form. A review with special emphasis on floating drug delivery system. Informa Health. 2011; 18(2): 97-110.

[9] Vyas SP, Khar RK. Controlled drug delivery: concept and advances. Delhi: Vallabh prakashan. 2002.

[10] Streubel A, Siepmann J, Bodmeier R Floating matrix tablets based on low density foam powder: effects of formulation and processing parameters on drug release. Eeuropean Journal of Pharmaceutical Sciences. 2003; 18(1): 37-45.

[11] Doshi SM, Tank HM,Gastro retention- An innovation ver conventional poorly soluble drugs :A Review . International Journal OF Phharmaceutical and Chemical Sciences. 2012; 1(2): 859-66.

[12] Mishra A, Gupta P. Gastroretentive drug delivery system: A Review. Internatonal Journal of Drug Development and Research. 2012; 4(4): 28-39.

[13] Pawar VK, Kansal S, Asthana S, Manish K. Chaurasia. Industrial perspective of gastroretentive drug deliery system: Physiochemical, Biopharmaceutics, Technological and Regulatory Considerations. Expert opinion on drug delivery. 2012; 9(5): 551-65.

[14] Arora S, Javed A, Ahuja A, Khar RK, Baboota S. Floating drug delivery system: a review. AAPS Pharm Sci Tech. 2000; 6(3): 372-90.

[15] Singh B, Kim KH. Floating drug delivery system: an approach to oral control drug delivery system via gastric retention . Journal of Contolled Release. 2006; 63(3): 235-59.

[16] Talukder R, Fassihi R. Gastroretentive delivery system. Drug Development and Industrial Pharmacy. 2004; 30(10): 1019-28.

[17] Prajapati VD, Jani GK, Khutliwala TA, Zala BS. An upcoming approach for gastroretentive drug delivery system. Journal of Controlled Release. 2013; 168(2): 151-65. 
[18] Kakar S, Batra D, Singh R, Nautiyal U. Magnetic microspheresas magical novel drug delivery system : A Review. Journal of Acute Diseases. 2013; 2(1): 1-12.

[19] Ito R, Machida Y, Sannan T, Nagai T. Magnetic granules: a novel system for specific drug delivery to oesophageal mucosa in oral administration. Int. J. Pharma. 1990; 61(2): 109-17.

[20] Waterman KC. A critical review of the gastric retentive controlled drug delivery . Pharmaceutical Development and Technology. 2007; 12(1): 1-10.

[21] Rathee P, Jain M, Rathee S, Nanda Arun, Hooda A. Gastroretentive drug delivery system: A Review of formulation approaches. The Pharma Innovation. 2012; 4(4): 147-50.

[22] Sauzet C, Claeys -Bruno M, Nicholes M, Kister J, Piccerelle P, Prinderre P. An innovation floating gastro retentive dosage system : Formulation and in vitro evaluation. International Journal of Pharmaceutics. 2009; 378(2): 239.

[23] Prassanakumara J, Ramarao T, Jayaveera KN. Modulation of gastro intestinal transit time by floating drug delivery system. Indo American journal of pharmaceutical research. 2012; 2(10): 1223-32.

[24] Mayavanshi AV, Gajjar SS. Floating drug delivery system to increase gastric retention of drugs. Research Journal of Pharmacy and Technology. 2008; 1(4): 345-8.

[25] Jamil F, Sunil K, Sharma S, Vishvakarma P, Singh L. Review on stomach specific drug delivery : development and evaluation. International Journal of Research in Pharmacy and Biosciences. 2011; 2(4): 1427-33.

[26] Groning R, Heun C. Oral dosage forms with controlled gastrointestinal transit drug delivery. Drug Development and Industrial Pharmacy. 1984; 10(4): 527-39.

[27] Agyilirah GA, Green M, Ducret R. Evaluation of gastric retention properties of cross linked polymer-coated tablet versus those of non disintegrating tablets. International Journal of Pharmaceutics. 1991; 75(2-3): 241-7.

[28] Sonar GS, Jain DK, Dhananjay M. Preparation and invitro evaluation of bilayer floating bioadhesive tablets of rosiglitazone maleate. Asian Journal of Pharmaceutical Sciences. 2007; 2(4): 161-9.

[29] Sruthy PN, Anoop KR. Formulation and evaluation of olmesartan medoxomil floating tablets. International Journal of Pharmacy and Pharmaceutical Sciences. 2013; 5(3): 691-6.

[30] Tanwar YS, Naruka PS, Ojha GR. Development and evaluation of floating microspheres of verapamil HCL . Brazilian Journal of Pharmaceutical Sciences. 2007; 43(4): 529-34.

[31] Chinthala SK, Kota SR, Hadassah MM, Sridevi S. Formulation and evaluation of gastroretentive floating tablets of gabapentin using effervescent technology. International Journal of Pharmaceutical and Biomedical Research. 2012; 3(4); 202-8.

[32] Vedha BN, Brahma RA, Samyuktha RB. Floating drug delivery of nevarapine as a gastroretentive system. Journal of Yung Pharmacist. 2010; 2(4): 350-5.

[33] Boldhane SP, Kuchekar BS. Development and optimization of metoprolol succinate gastroretentive drug delivery system . Acta Pharma. 2010; 60(4): 415-425.

[34] Bhowmik D, Chiranjib B, Chandira M, Jayakar B, Sampath. Kumar KP. Floating drug delivery system. Der Pharmacia Lettre. 2009; 1(2): 199-218.

[35] Chander S, Shireesh K, Nagendra B. Preparation and evaluation of gastroretentive floating tablets of ketoconazole. International journal of pharmaceutical research and development. 2010; 2(9): 175-84.

[36] Chandel A, Chauhan K, Parashar B, Kumar H, Arora S. Floating drug delivery systems: A better approach. International Current Pharmaceutical Journal. 2012; 1(5): 110-18. 